\title{
Limiting Learning Environments through Domestication
}

\author{
Stefani Boutelier* \\ Aquinas College \\ *Corresponding Author: smb009@aquinas.edu \\ Received : 2018-12-10 \\ Accepted : 2019-04-29
}

How to cite this paper: Boutelier, S., (2019). Limiting Learning Environments through Domestication, Journal of Culture and Values in Education, Volume 2 (1), 45-55.

\section{Abstract}

This theoretically based paper analyzes the proliferation of domestication in our education systems inside and outside of the classroom. Looking at past and current trends, questions are posed and suggestions are made to break these cycles. Don Miguel Ruiz's definition of domestication of children frames this paper and engages the reader to question their current practices and expectations of children and/or students.

Keywords: Domestication, Critical Pedagogy, Praxis, Culturally Relevant Teaching

\section{Introduction}

"Sit," "stay," "come," are all commands associated with a trained, domesticated animal. Not often do we correlate domestication with humans, after all, aren't we born domesticated? Yet, ponder how domesticating is meant to cultivate a trained mammal to follow rules, cultivate expectations, and fit into a mold. Now this sounds more like house-breaking a human. It does sound dirty and against humanity to word it this way but as don Miguel Ruiz (1997) explains in his best-selling philosophical guide, The Four Agreements, children are domesticated at home by being told what to do, being held to specific expectations, and guided to act in certain ways. The cultural values placed on this domestication is how we often view success in a classroom and for life. Then we continue to socialize students because teachers (K-Higher ed.) are still domesticated in a way for learning, attending, and reacting the "expected" way.

This paper will analyze these conjectures from different levels of learning, relationships, and how they perpetuate through families and into educational realms. Theoretical frameworks of culturally responsive teaching and critical pedagogy will be integrated. They have evolved and supported change. These frameworks ignite conversations related to power, thought, and breaking systemic education dynamics which keep us at bay. A critical pedagogy framework has always supported a student-centered approach which is now at the forefront of teaching models (Freire, 2006). A culturally relevant classroom implores the use of reflection, relationships, facilitation, and collaboration (Gay, 2002; Ladson-Billings, 2014). Equity literacy 
overlaps with these frameworks and others to encourage teachers and learners to evaluate, interact, and utilize curricula to interrupt current social structures (Freire, 2006; Gorski, 2017). These frameworks and suggestions have intentions to move us to understand domestication and beyond this concept to analyze familial cultural values as part of the marginalizing factors that keep our education system static.

The goal of this paper is to bring these ideas to the forefront of education to help act as a catalyst for humanizing and releasing privileged dynamics that do not provide for a justice-filled learning environment. Common phrases related to domestication of schooling will be interplayed throughout the text in isolation to allow the reader to inquire and self-reflect about how these expectations apply to success and to consider how they can be broken. Questions are posed to get you thinking and reflecting on your own practice as an educator, parent, and/or citizen. It also has a few references to works that are not timely by any current writing standards. The point of this is to show how long these ideas have been brewing. If you are reading this, you no doubt know how challenging it is to manipulate the education system or any cultural mainstay in the United States. Farming schedules and factory jobs are not taking over the world. Yet, rumor has it, automation might, therefore if our system breeds critical and creative thinkers, new jobs and skills will be created and needed in our future job markets to balance the automation domination.

\section{I must listen and follow directions.}

We don't choose our language or religion when born; we don't choose our culture or locale. Our name is chosen for us; how we are parented and educated are also in line. And more importantly we don't choose the moral values (Ruiz, 1997) that welcome us and rear us. Ruiz explains that we have words that define us (e.g., woman, man, child, adult) and a reward system along with consequences based upon the trained interpretations of these words. This is Ruiz's process of domestication. It feeds into our communities, our cultures, and our schools. We must disrupt this system plaguing our learning environments--it is difficult to teach anyone who enters a classroom without an open-mind. Postman and Weingartner (1969), among others, have advocated for nearly 50 years to disrupt our thinking and our toxic, plateaued education system. Illich (1971) questioned how we institutionalized characteristics of our identity through schooling. And Reimer (1971) acknowledged society should be challenging the indoctrination in schools. Why has it taken so long and how do we break this?

\section{The teacher is in control.}

These colonized methods of behavior increase power structures in our classrooms and are difficult behaviors to "break" in teacher candidates and teacher educators (Foucault, 2006; McLaren, 2003). If our teachers cannot move beyond these domesticated behaviors as students, we cannot expect critical dialogue and action to occur in primary and secondary settings. Teacher educators play a strong role in helping break these cycles. 


\section{Parents versus Teachers}

Adults have expectations. These expectations filter out to our children. These domesticated behaviors then filter into schools and academic behavior. Often, parents domesticate their children with an expected behavior in the classroom--this is often culturally embedded. Some children are trained to only listen to teachers and never question, others are raised to voice their opinion and question the content. This is where teachers come in. Teachers must be trained and aware of the domesticated behaviors of their students and understand the variance of demand on their students. Furthermore, teachers must become aware of their own domestication, which has been engrained longer than our students.

How do we start this? Like anything, we must first identify our own teaching philosophies and build upon the domestication instilled at home. Having students sit in rows, raise their hands to respond, ask to use the restroom are only a few examples. What are these behaviors for? Control, power, obedience--the synonyms can go on. Yes, these behaviors help with order and may make teaching easier, but are we ultimately teaching for today or do we want to create citizens who can survive and thrive in the future? Peddiwell discussed this with satire in his Saber Tooth Curriculum (1939) bringing to light the debate of teaching for survival today or teaching for survival tomorrow. What will it be?

I don't want to be creative, I just want to finish it.

Parental involvement plays a vital role, as proven through experience and research. Educators only have control over our continued domestication in our classrooms and during the time we work with students. The first step is awareness. We should not be viewing this as a competition of parents versus teachers. The priority is always our children/students. Working together is part of a mutual process (Freire, 2007) needed to expand our future generations.

\section{Breaking the Cycle with Teacher Candidates}

Many traditional aged teacher candidates should have or could have had a more progressive learning environment, after all there are options now--PBL, STEM, critical thinking, ...but where is the ownership? The creativity? The autonomous learning that often gets thrown out? Teacher candidates are still fighting counter-domestication. They still want to be told what to do and not embrace autonomy in assignments. This needs to change, but how?

Paolo Freire's work and theory of critical pedagogy is one method to guide us in this work against trained socialization. His theory (2007) supports those who are marginalized by providing students with methods and the power to "liberate themselves" and others (p. 44). The opposite of this would be our traditional, domesticized means of teaching--having control and telling our students what to do. We are all guided by these rules and rarely fight it. Students in higher education are still trapped in these domesticized learning environments. Even with highly publicized 21st century skills promoting facilitation, all levels of education still resort back to models that thrive on the dynamics of power and simple direct instruction (Foucault, 2006; Freire, 2007). 
College is the only outlet for success.

Power is the antithesis of the critical pedagogically-minded instructor. One must relinquish power to provide means for students to identify and lead their own movements of learning to better themselves and "detach the power of truth from forms of hegemony, social, economic, and cultural, within which it operates at the present time" (Foucault, 2006, p. 171). Critical pedagogy can be applied in teacher education programs to engage preservice teachers to break these cycles. This must be done purposefully and with scaffolds to simultaneously teach the critical pedagogy model and integrate praxis (theory put into action) in the work of the learners and educators (Freire, 2007; Mclaren, 2003).

Teacher educators often assume that all candidates who want to become teachers arrive with advocacy mindsets, critical analysis skills, and understanding of how to disrupt their own domestication. As teacher educators themselves might not be clear about the terminology of domestication, the concept must be analyzed and learned. If we consider a traditional undergraduate who is near completion of teacher certification, their age (i.e., 21-23) categorizes them near, but not at full brain maturity--which is identified as 25 (Johnson, Blum, \& Giedd, 2009). Although this paper will not expand on the brain development piece, it is to point out how the force of the domesticated brain could be fogging the expansion of thought and action through teacher education courses.

Critical thinking skills become a great protocol to continue to integrate and teach for all content teachers. Modeling and providing for civil discourse around the topic of domestication is one avenue to start. We can incorporate a lens of critical pedagogy, culturally responsiveness, and self-advocacy for teacher candidates to incorporate these skills and create procedures or activities to empower themselves and future students. Costa's (2001) promotion of the teaching of, for, and about thinking spans across all age groups--we never stop thinking. These three concepts are often defined as metacognition but unless we practice and make this a habit, we will lack the skills for ourselves and thus will not be able to transfer these abilities to our students.

I'll assume there is a reason I need to learn this.

We can promote an authentic "learning experience" where the active interaction between learning and the student is what creates the transferable knowledge (Tyler, 1969, p. 63). Freire (2007) discussed the cliché of giving a little to get a little; educating and learning is a mutual process. Teacher educators must model these and provide varied methods of instruction to disrupt all levels of education. Teacher educators, teachers, and parents should not expect change without changing themselves.

Returning back to Ruiz (1997), his concept of domestication is presented prior to explanation of his four agreements which are: Don't take things personal, Be immepcialbe with your words, Don't make Assumptions, and Always do your best. We can look at these rules as one guiding arena to merge from traditional thought and negativity. Would this however, simply disrupt 
the role of domestication? How much disruption is needed to make a cultural shift? And even greater a question, how do we get buy in?

I must raise my hand before talking.

We need to scaffold these ideas through education programs, then through the K-12 system, and finally in the homes--or vice versa. These shifts are never easy, nor fast. Training teachers to first identify, then disseminate a deeper thinking model is one way to break from traditional expectations and start this shift.

\section{Domestication at the Surface Level}

We have potential beyond birth (Cantor, Osher, Berg, Steyer, \& Rose, 2018) which can go beyond the limitations and expectations we are born into. We must recall and revitalize the notion of domestication as not something that is static, but fluid. Humans learn from all contextual environments which should help us move beyond the sense of a single form of growth in the classroom (e.g., teaching to the test) to a multidimensional curriculum (e.g., social, emotional, academic) (Gay, 2000). This must include understanding what deeper levels of culture represent (Hammond, 2015). As well, a plethora of research continues to support the need for relationships and cultural influences in the curriculum (Cantor et al., 2018; Emdin, 2016; Ladson-Billings, 2014).

When we look at some of the demographics and understand how we learn differently based on our culture or location, we must be clear not to categorize certain conditions (e.g, poverty) as part of one's domesticated culture (Gay, 2002; Gorski and Swalwell, 2015; Hammond, 2015; Ladson-Billings, 2014). This is not to say that certain living conditions do not attribute to one's personality, experience, or access, but to identify these factors as static versus malleable continues marginalization that must be countered. Through a critical lens and an acknowledgement of these factors one can separate domestication and culture.

My test scores define my intelligence.

Hammond (2015) describes surface level culture as observable and manicured--it's what we see and how we create stereotypes. Domestication at the surface level could be defined as manners, forms of dress or physical appearance, and material belongings. Most often children are domesticated at this level to confirm they will "fit" into society, into their classrooms, and with their peers. As we know, anyone who doesn't fit this can be bullied, isolated, or even labeled "weird." Ah, the mouth of babes can be harmful and yet, where and when is this behavior domesticated?

If we compare a deep culture of collectivism, unconsciousness, spirituality, and world views to the concept of domestication we begin to envision similar parallels (Hammond, 2015; Illich, 1969). Are these categories also not built on the foundations of one's domestication? The environment and cultural context builds the behavior of collectivism (e.g., race, language, amount of siblings, chores). Our unconsciousness and world view can be a pillar filled with all 
of these domesticated settings. Finally, Hammond also points out how spirituality can fulfill a variety of places of domestication (e.g., higher being, connection to the world, morals, thinking).

\section{I pledge allegiance...}

With this analysis, can we adhere to the notion that domestication is unavoidable? What role does education play in this? Many would argue, often parents domesticate children to be "successful" in school. Because if you are not successful in the school environment, you risk...(fill-in the blank). The irony comes in the attempt to not domesticate, if so, can you succeed, be happy, or fulfill your goals if you are not domesticated?

Many of these surface cultural values are embedded into the curricula across all levels. Freire's (2007) concept of banking is similar to the domesticated education concept addressed here. Domestication is the mindset we are trained at home to follow. The banking system is how educators deposit information while our students "receive, memorize, and repeat" (Freire, 2007, p. 72). This model perpetuates and limits one's thinking and ability of choice. This encourages every student to be required to know the same, act the same, and fall in line with the greater expectations of society. Our knowledge base often categorizes us in society. However, knowing an abundance of facts (useless or valuable based on context) does not lead one towards success, happiness, or a certain career. And isn't this the goal?

Just tell me how I can earn an A.

Osher, Cantor, Berg, Steyer, and Rose (2018) describe micro contexts that increase our relationships to others (e.g., socioeconomic status, race, peers). These surface level identifiers might have a deeper level context in regards to the effect they make on one's whole self. Identifying and acknowledging this interconnectedness allows for parents, teachers, and teacher educators to create environments of exposure in all variable contexts. This can be done through open dialogue, readings, media, and the connection to others. We can utilize the cultural teachings from home and positive domestication to learn from and with others--that mutual process (Freire, 2007) of an authentic learning environment is feasible.

\section{Counter-Domestication}

If domestication, for the sake of this article, means to mold into the status quo, then counterdomestication would allow for a child, for a learner, for a human to develop through choice and without judgement or guidance. This alone sounds shocking and might take a moment to process. Go ahead, take a few minutes to ponder choice and the act of giving autonomy. This can wait. If you choose to not finish this article and decide to delve deeper into tools that will help you support this type of educating, then by all means, go forth and break the cycle. If you feel the need to continue reading this article for purpose of understanding, summary and authentic referencing, then hold yourself to the understanding that you are domesticated. You are following the rules. This article follows the rules. Often academic writing, even when theoretical, is by the book. If not, is it judged? Delineated? Un-scholarly? It definitely isn't accepted. And how do we break a cycle that perpetuates itself? 
Endless books and articles hint or explicitly identify the need to call out privilege and disregard the comfort level of the hegemony (i.e., educated white males). Narratives in schools, media, and history books still dominate the perspective of whites. The Zinn Foundation and Teaching Tolerance are only two popular outlets to start providing counter-narratives in our classrooms (e.g., looking at slave and indigenous narratives during times of colonization which is often taught through the eye of the heroic conqueror and explorer). Yet, if domestication at home continues to perpetuate these ideas and if we cannot guarantee the quality of the counternarratives in our curriculum, we will continue in negative spirals. And if we provide counternarratives only in piecemeal or short-term lessons, how do we authentically educate?

Hammond (2015) discusses cultural archetypes as self-versus group. Could we consider the protocols of moving from teaching self-agency to group-agency as one step in the movement away from domestication? That is to assume the American domestication of individualism is dominant. Is it? Or do we think this due to the voice of the powerful and the actions of those in charge?

\section{My interests have no place in school.}

We have a world to share and it seems to feel smaller every day. If we perpetuate a domestication of our smallest humans, we will continue the current cycle of hate, distrust, and ultimate destruction. Emdin (2015) explains "the point is not to force everyone to be a part of the dominant culture, but rather to move everyone to be themselves together," (p. 109). We must take learning environments as they are meant to be: to expand one's thinking and interpret all the knowledge we are given to be part of this great world.

\section{Domesticating the "white" way}

If we look at the root of domesticating, it fits into parameters of power, control, and the factory model of education. These are traditional white expectations of comfort and power. This is an issue because it manipulates expectations and brings forth the colonialist idea that there is only one right way. Culturally responsive teaching is one lens that has been integrated into education to focus on individuals and make the classroom inclusive at all levels (Gay, 2002; Hammond, 2015; Ladson-Billings, 2014).

If you've read any socially just, culturally relevant, or progressive education articles, books, or theories, it is clear that education has and is still dominated by white, colonial ways. And for the most part, domestication across homes is presumably the same. The idea to survive the colonial ways of the streets, the job market, and classrooms are part of this. If one is labeled with Learning Disabilities or as an English Learner, the stakes are even higher. This leaves many students to start out with labeled deficits (Hammond, 2015) and the need to further climb creates more obstacles for our marginalized students.

My voice is not valued. 
Literacy teaching doesn't stop when a child demonstrates mastery of reading or in 3rd grade. Reading and writing skills become a dominant sub-point in domestication. Even more important might be the skill of code-switching (when one changes linguistic abilities based on the context and the people involved). This, unfortunately, can be a necessary skill for life--or to sustain life. Many people of color have to navigate different worlds and different conceptions of domestication. It is critical that white teachers understand this. Considering Gorski's (2017) equity literacy of recognizing, responding, and redressing bias in classrooms and then committing to address and sustain a bias-free environment allows classrooms to become more inclusive by supporting the elements of domestication that run culturally through the threads of our diverse society. Myths related to literacy often challenge the assumption that reading and writing are the only needed literacy skills, however, Lee (2011) acknowledges that literacy and action (consistent with praxis) lead to critical learners and movement. Mix these lenses with integration of critical pedagogy in one's teaching framework and movement to break these cycles continue.

Identification and awareness of literacy through the "white" way becomes dangerous and has continued to limit the lenses of our students. We need diverse voices represented and we need to scaffold norms of conversation to increase critical thinking and bring about action/change. Literacies fulfill most of our interactions (e.g, cultural literacy, media literacy, social literacy). All forms of literacy must be exposed and utilized to "just"ify our learning environments.

\section{Praxis to Disrupt Domestication}

Praxis is the action, reflection, and merging of theory as an application to make change (Freire, 2007). Education hails the use of data-driven practices, paradoxically we often find research supporting both sides. Kohn (2011) makes the case that students learn more when they are allowed choice and are interested while research and experience continues to demonstrate to us through multiple lenses (e.g., cultural relevance, topic choice, student agency) which provide our domesticated personalities with the ownership to move us beyond our current roles. It's not always apparent which dichotomy is dominant in research, however, concepts consistently standing out are thinking, culture, and relationships. All of these theories are also supported by brain research.

There isn't opposing literature, or at least not significant enough to be identified, that states we should not improve thinking, we should not ignore culture, and we should not cultivate relationships. It is clear, far beyond these references (Emdin, 2015; Foucault, 2006; Freire, 2007; Gay, 2000; Hammond, 2015; Illich, 1969; Kohn, 2011), that relationship and authenticity in our learning need to be undomesticized. Undomesticize is created for this paper as the process of breaking the cycle of expectation and behavior to satisfy the traditional conjectures of our society. Breaking power structures, building relationships, emending facilitation, and offering authentic choice can be a catalyst for this change. It is a summons to break from dominant ideologies. This is a challenge for parents, teachers, and teacher educators to address this more and bring about effective praxis for change to allow for critical learners and community activists. Partner with parents, nonprofits and neighborhood support systems. Encourage dialogue about domestication and how the acknowledgement of this will encourage growth. Educate 
with an open mind and provide choice. With these we can break cycles of conformity and domestication. 


\section{References}

Cantor, P., Osher, D., Berg, J., Steyer, L. \& Rose, T. (2018). Malleability, plasticity, and individuality: How children learn and develop in context. Applied Developmental Science. DOI: 10.1080/10888691.2017.1398649

Costa, A. (Ed.). (2001). "Teaching for, of, and about thinking." in Developing Minds: A resource book for teaching thinking (3rd ed.). Virginia: ACSD.

Emdin, C. (2016). For White Folks Who Teach in the Hood... and the Rest of Y'all too. Boston: Beacon Press.

Foucault, M. (2006). Truth and Power. In Chomsky, N. \& Foucault, M. The Chomsky-Foucault Debate: On human nature. (pp. 140-171). New York: The New Press.

Freire, P. (2007). Pedagogy of the Oppressed: 30th anniversary edition. New York: Continuum.

Gay, G. (2000). Culturally Responsive Teaching: Theory, Research, and Practice. New York:

Teacher College Press.

Gay, G. (2002). Preparing for culturally responsive teaching. Journal of Teacher Education, 53(2), 106-116. doi:10.1177/0022487102053002003

Gorski, P. \& Swalwell, K. (2015). Equity Literacy for All. Educational Leadership. ASCD.

Gorski, P. (2017). Equity Literacy for Educators: Definitions and abilities. Equity Literacy Institute. Retrieved from http://www.edchange.org/handouts/

Equity-Literacy-Intro-Abilities.pdf

Hammond, Z. (2015). Culturally Responsive Teaching and the Brain. Thousand Oaks, CA: Corwin.

Illich, I. (1971). Deschooling Society. New York: Harper \& Row

Johnson, S., Blum, R., \& Gieed, J. (2009). Adolescent Maturity and the Brain: The Promise and Pitfalls of Neuroscience Research in Adolescent Health Policy. J Adolesc Health. 45(3) 216-221. doi:10.1016/j.jadohealth.2009.05.016

Kohn, A. (2011). "Well, Duh!" - Ten Obvious Truths That We Shouldn't Be Ignoring. American School Board Journal. Retrieved from https://www.alfiekohn.org/article/well-duh-ten-obvioustruths-shouldnt-ignoring/

Ladson-Billings, G. (2014). Culturally relevant pedagogy 2.0: A.k.a. the remix. Harvard Educational Review, 84(1), 74-84.

Lee, C. J. (2011). Myths about critical literacy: What teachers need to unlearn. Journal of 
Language and Literacy Education, 7(1), 95-102. Retrieved from

http://www.coa.uga.edu/jolle/2011 1/lee.pdf

McLaren, P. (2003). Revolutionary Pedagogy in Post-Revolutionary Times: Rethinking the political economy of critical education. In Darder, A., Baltodano, M. \& Torres, R. D. (Eds.) The Critical Pedagogy Reader. Great Britain: Taylor \& Francis Books.

Osher, D., Cantor, P., Berg, J., Steyer, L. \& Rose, T. (2018). Drivers of Human Development: How relationships and context shape learning and development. Applied Developmental Science. DOI: 10.1080/10888691.2017.1398650

Peddiwell, J. (1939). The Saber-tooth Curriculum. McGraw Hill: New York.

Postman, N. \& Weingartner, C. (1969). Teaching as a Subversive Activity. New York: A Delta Book.

Reimer, E. (1971). School is Dead: An essay on alternatives in education. New York: Penguin Press.

Ruiz, d. M. (1997). The Four Agreements: A Practical Guide to Personal Freedom (A Toltec Wisdom Book). San Rafael, CA: Amber-Allen Publishing.

Tyler, R. W. (1969). The Basics of Curriculum and Instruction. Chicago, IL: University of Chicago Press. 